\title{
Iron Uptake Analysis in a Set of Clinical Isolates of Pseudomonas putida
}

\author{
Lázaro Molina ${ }^{1 *}$, Valérie A. Geoffroy ${ }^{2}$, Ana Segura ${ }^{1}$, Zulema Udaondo ${ }^{1 \dagger}$ and \\ Juan-Luis Ramos ${ }^{1+}$ \\ ${ }^{1}$ Environmental Protection Department, Estación Experimental del Zaidín, Consejo Superior de Investigaciones Cientificas, \\ Granada, Spain, ${ }^{2}$ Centre National de la Recherche Scientifique, UMR 7242, Université de Strasbourg, (ESBS), IIlkirch, France
}

\section{OPEN ACCESS}

Edited by:

Martin G. Klotz,

City University of New York, USA

Reviewed by:

Michael L. Vasil,

University of Colorado Denver School

of Medicine, USA

John R. Battista,

Louisiana State University, USA

Paolo Visca,

Roma Tre University, Italy

*Correspondence:

Lázaro Molina

lazaro.molina@eez.csic.es

${ }^{\dagger}$ Present Address:

Zulema Udaondo and Juan-Luis Ramos,

Abengoa Research, Sevilla, Spain

Specialty section:

This article was submitted to

Evolutionary and Genomic

Microbiology,

a section of the journal

Frontiers in Microbiology

Received: 12 July 2016 Accepted: 12 December 2016 Published: 27 December 2016

Citation:

Molina L, Geoffroy VA, Segura A, Udaondo $Z$ and Ramos J-L (2016) Iron Uptake Analysis in a Set of Clinical Isolates of Pseudomonas putida. Front. Microbiol. 7:2100 doi: 10.3389/fmicb.2016.02100
Pseudomonas putida strains are frequent inhabitants of soil and aquatic niches and they are occasionally isolated from hospital environments. As the available iron sources in human tissues, edaphic, and aquatic niches are different, we have analyzed iron-uptake related genes in different $P$. putida strains that were isolated from all these environments. We found that these isolates can be grouped into different clades according to the genetics of siderophore biosynthesis and recycling. The pyoverdine locus of the six $P$. putida clinical isolates that have so far been completely sequenced, are not closely related; three strains (P. putida HB13667, HB3267, and NBRC14164T) are grouped in Clade I and the other three in Clade II, suggesting possible different origins and evolution. In one clinical strain, P. putida HB4184, the production of siderophores is induced under high osmolarity conditions. The pyoverdine locus in this strain is closely related to that of strain P. putida HB001 which was isolated from sandy shore soil of the Yellow Sea in Korean marine sand, suggesting their possible origin, and evolution. The acquisition of two unique TonB-dependent transporters for xenosiderophore acquisition, similar to those existing in the opportunistic pathogen $P$. aeruginosa $\mathrm{PAO}$, is an interesting adaptation trait of the clinical strain P. putida H8234 that may confer adaptive advantages under low iron availability conditions.

Keywords: siderophores, pyoverdine, iron, clinical strains, Pseudomonas putida

\section{INTRODUCTION}

Pseudomonas putida is a species that is widely distributed in the environment, being particularly abundant in rhizospheric, and bulk soil (Molina et al., 2000; Fernández et al., 2013; GarcíaSalamanca et al., 2013), as well as in fresh water communities (Maki et al., 1994; Li et al., 2012; Udaondo et al., 2012). Recently, a few P. putida strains have been isolated from hospital environments (von Graevenitz and Weinstein, 1971; Galli et al., 1992; Yoshino et al., 2011; Molina et al., 2013, 2014, 2016). The ubiquitous character of this microorganism has been linked to its broad metabolic potential, its ability to produce a large variety of secondary metabolites that may enable colonization of different environments and a complex array of sigma factors and twocomponent regulatory systems that allow a fast adaptation to environmental changes (Matilla et al., 2011; Udaondo et al., 2012, 2013, 2016; Planchamp et al., 2015). 
Iron has been recognized as a limiting nutrient and consequently, microbes have to assure iron sensing and uptake in each of the niches they colonize. The main mechanism for capturing iron is through high affinity of siderophores (Payne, 1980; Schalk and Guillon, 2013; Gasser et al., 2015). P. putida produces a main siderophore that has been previously identified as pyoverdine (Matthijs et al., 2009). From a chemical point of view, pyoverdine has a structure made up of three distinct elements: a quinoline-1-carboxylic acid moiety that contains a chromophore responsible for green fluorescence (a feature that is highly conserved in all the described pyoverdines); a dicarboxylic acid or its monoamide, bound as an amide to the 5-amino group of the chromophore; and a peptidic chain comprised of 6-14 amino acids bound to the carboxyl group of the quinoline (Meyer, 2000; Visca et al., 2007; Cornelis, 2010). Different types of pyoverdine have been found at the species level; these are often visualized by different band patterns in isoelectric focusing (IEF) gels, a method termed siderotyping that has been used as a taxonomic tool (Koedam et al., 1994; Fuchs et al., 2001; Meyer et al., 2007, 2008; Ye et al., 2013). In P. putida strains, siderotyping correlates with the phylogeny of genes involved in pyoverdine production, and it was found to be useful in distinguishing different P. putida strains (Meyer et al., 2007; Ye et al., 2013). Pyoverdine binds iron with high affinity and the complex is recognized by an outer membrane receptor named FpvA. The FpvA protein has been used as a phylogenetic marker because it shows high divergence and substantial intratype variation, and it has been shown that this variability is not generated by recombination (Smith et al., 2005).

In addition to self-produced pyoverdines, $P$. putida strains are able to take up iron through the acquisition of siderophores produced by other microorganisms (xenosiderophores); for this acquisition, $P$. putida utilizes a number of TonB-dependent membrane transporters. The large number of these transporters found in $P$. putida genomes correlates with their capacity for adaptation to changing environments and enhanced niche colonization (Martínez-Bueno et al., 2002; Cornelis, 2010; Nader et al., 2011).

The aim of this study was to study the iron uptake systems (pyoverdine locus and iron-related TonB-dependent transporters) in a set of clinical $P$. putida strains to try to understand the impact of the iron uptake systems on the capacity of clinical strains to colonize and survive in humans tissues. To this end, we used annotated genomes from $P$. putida strains available in the NCBI data base (http://www.ncbi.nlm.nih.gov/genome/?term = putida, May 2016), that includes six clinical $P$. putida isolates, to carry out in silico studies of the pyoverdine locus and the TonB-dependent transporters. To support the bioinformatic studies we have used four available $P$. putida clinical strains. The four strains were isolated at the Hospital of Besançon (France). P. putida HB13667 and H8234 were isolated from the blood of two in-patients presenting general bacteremia (Molina et al., 2013, 2016); $P$. putida HB4184 was isolated from sputum of a cystic-fibrosis patient (Molina et al., 2016); and P. putida HB3267 which exhibits an antibiotic multi-resistant phenotype and was isolated from the blood of a deceased in-patient (Molina et al., 2014, 2016).
Our analyses indicate that $P$. putida strains can be classified into five clearly defined clades on the basis of the homology of proteins related with pyoverdin production and that the six clinical isolates belong to two different clades suggesting that they have at least two different phylogenic origins. Strain P. putida H4184 shares many common siderophore-related elements with one rhizobacteria strain ( $P$. putida B001) isolated from high osmolarity environments; accordingly, we have demonstrated that this strain produces a large amount of siderophores under high osmolarity conditions.

Interestingly, the clinical strain P. putida H8234 presented two unique TonB-related transporters, similar to those of the opportunistic pathogen $P$. aeruginosa $\mathrm{PAO}$; these transporters can confer selective advantages against other $P$. putida strains in environments with a low iron content.

\section{MATERIALS AND METHODS}

\section{Bioinformatic Analysis}

All the strains used in this study are listed in Table 1. Their sequences are available in the GenBank data base. Genome comparisons to determine protein homology, common genes, and genomic organization were performed using the RAST software (Aziz et al., 2008) and BLASTp.

Phylogenetic studies of individual proteins were performed using the platform Phylogeny.fr (http://www.phylogeny.fr/) (Dereeper et al., 2008). Phylogenetic studies of complete genomes were performed using Composition Vector Tree (http://tlife.fudan.edu.cn/cvtree/). These phylogenetic studies were carried out as recommended by the user manual (http://tife.fudan.edu.cn/cvtree/help/index.html) with a Kpeptide length of 6 , as recommended by the authors for prokaryote organisms (Xu and Hao, 2009).

The pyoverdine peptide chain was predicted using the non-ribosomal peptide synthase substrate predictor NRPSsp (http://nrpssp.com/execute.php), NRPSpredictor2 (http://nrps.informatik.uni-tuebingen.de), and PKS/NRPS programs (http://nrps.igs.umaryland.edu/) for pyoverdine synthetases.

TonB-dependent transporters were identified by selecting TonB annotated proteins from the genomes of the microorganisms used in this study using the RAST Annotation Server (http://rast.nmpdr.org/rast.cgi) and the set of sequences deposited in Genbank (https://www.ncbi.nlm.nih.gov/genbank/). We selected TonBtransporter proteins bearing the characteristic domains of siderophore transporters by application of InterPro (http://www.ebi.ac.uk/interpro/) and Blastp web sites that provide functional analysis. Exclusive TonB-dependent transporters were those presenting $<80 \%$ identity in the amino-acid sequence with others present in $P$. putida strains.

\section{Production of Pyoverdine}

Cells were pre-grown in M9 minimal media (Abril et al., 1989) with glucose $(5 \mathrm{mM})$ as the sole carbon source. The overnight cultures were washed three times and re-suspended to reach $\mathrm{OD}_{660 \mathrm{~nm}}$ of 0.1 in M9-glucose. Salt conditions were adjusted 


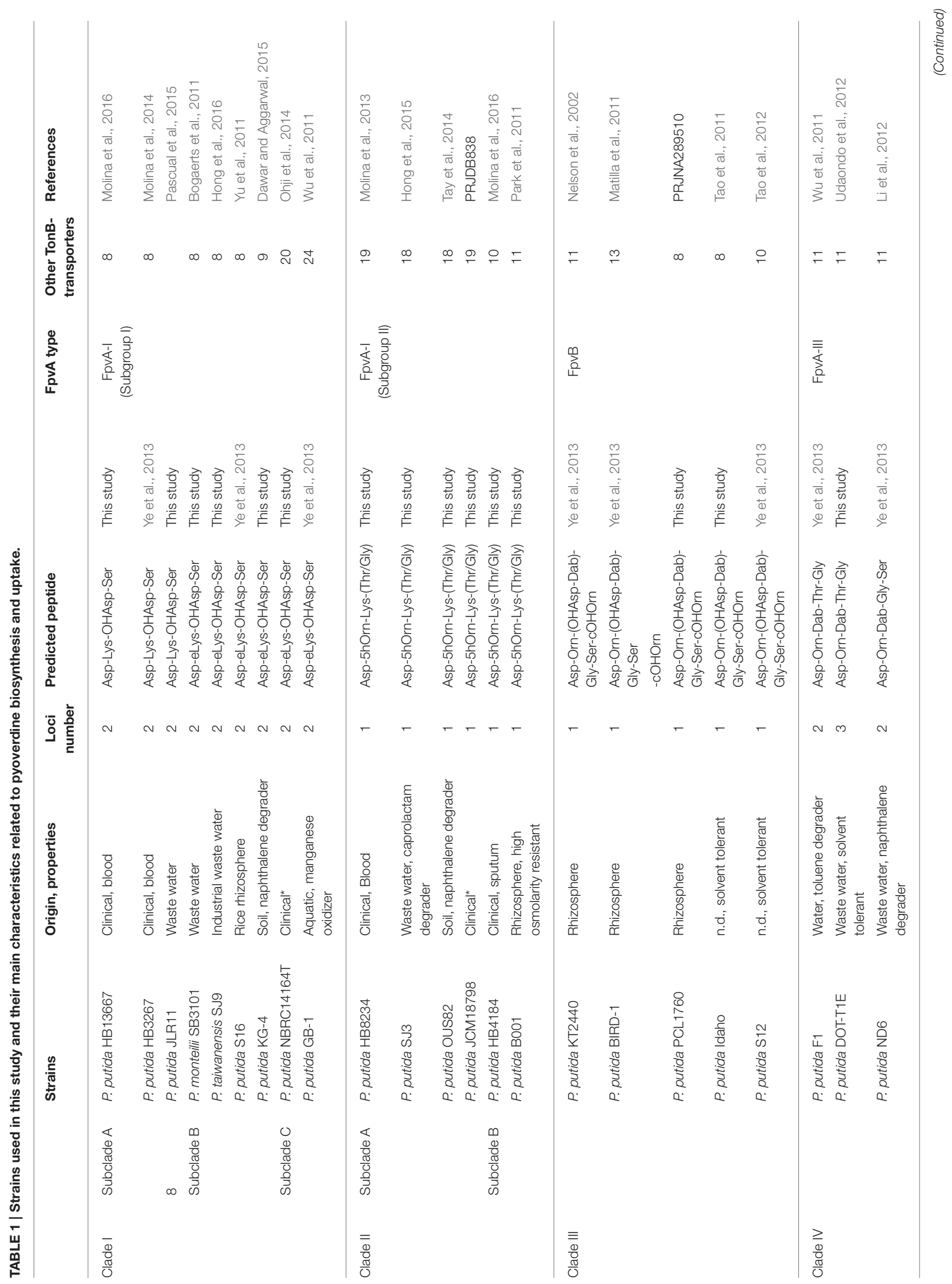




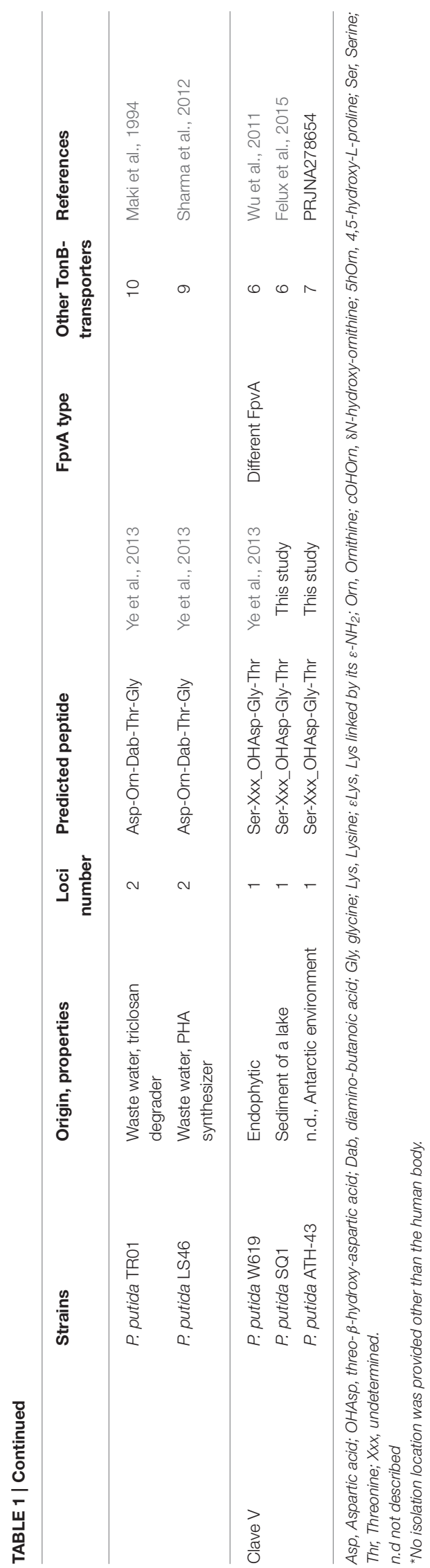

to 0.05 or $0.9 \% \mathrm{w} / \mathrm{v}$ of $\mathrm{NaCl}$ in the low and high osmolarity media respectively. When indicated the iron chelator EDDHA was added to reach a final concentration of $20 \mu \mathrm{M}$. The visual and spectrophotochemical detection of pyoverdine production was performed as indicated by Bultreys et al. (2001). The production of pyoverdine-type siderophores was visualized as maximum absorption at 365,375 , and $410 \mathrm{~nm}$.

\section{IEF Analyses Of Pyoverdines}

Supernantants of cultures grown with $5 \mathrm{~g} / \mathrm{L}$ of casamino acids (CAA) supplemented with $\mathrm{MgSO}_{4} 7 \mathrm{H}_{2} 0(0.25 \mathrm{~g} / \mathrm{L})$ and $\mathrm{K}_{2} \mathrm{HPO}_{4}$ $(1.18 \mathrm{~g} / \mathrm{L})$ were analyzed by IEF according to the method described by Koedam et al. (1994). Pyoverdine was separated in polyacrylamide $(5 \%)$ gels $(125 \times 65 \times 0.4 \mathrm{~mm})$ containing $2 \%$ ampholines (Byolyte 3/10 from Bio-Rad) to develop a $\mathrm{pH}$ gradient from 3.5 to 9.3 during electrophoresis in model 111 Mini IEF Cell. Preparation of the gels and electrophoresis conditions were those recommended by the manufacturer. Samples of $1 \mu l$ of the 20-fold-concentrated (through lyophilisation) CAA-culture supernatants were loaded. Samples were run at $4^{\circ} \mathrm{C}$ for $1.5 \mathrm{~h}$ at constant power $(12 \mathrm{~W})$ with voltage from $200 \mathrm{~V}$ at the beginning to $1000 \mathrm{~V}$ at the end of the electrophoresis. Immediately after the run, the fluorescent bands of pyoverdines were visualized under UV light at $365 \mathrm{~nm}$.

\section{Siderophore Uptake Experiments}

Siderophore-mediated iron uptake was performed as described by Fuchs et al. (2001) and adapted by Hoegy and Schalk (2014). Briefly, labeled ferrisiderophores were prepared by mixing a $4 \mu \mathrm{l}$ ${ }^{55} \mathrm{FeCl}_{3} 250 \mu \mathrm{M}$ (Amersham) with $4 \mu \mathrm{l}$ of a $1 \mathrm{mM}$ pyoverdine solution obtained from the cultures of the different strains. After $30 \mathrm{~min}$ of incubation at room temperature, this mixture was diluted with Tris- $\mathrm{HCl} \mathrm{pH} 8(50 \mathrm{mM})$ to obtain a $10 \mu \mathrm{M}$ siderophore $-{ }^{55} \mathrm{Fe}$ complex.

Pseudomonas strains to be used as siderophore uptaking cells were grown in CAA medium for $24 \mathrm{~h}$ at $30^{\circ} \mathrm{C}$. Then, bacterial cells were washed twice in CAA medium to remove the native siderophore and were re-suspended in Tris- $\mathrm{HCl} \mathrm{pH} 8(50 \mathrm{mM})$ to reach an optical density of 1 at $600 \mathrm{~nm}$.

Five microlitres of siderophore- ${ }^{55} \mathrm{Fe}$ complex were mixed with $500 \mu \mathrm{l}$ of the cell suspension and incubated for $30 \mathrm{~min}$ at $30^{\circ} \mathrm{C}$. Then, $100 \mu \mathrm{l}$ of the labeled bacterial cells were withdrawn and rapidly filtered through $0.45 \mu \mathrm{m}$ membranes (Whatmann GFB filters). The cells remaining on the filters were thoroughly washed twice with Tris- $\mathrm{HCl} \mathrm{pH} 8(50 \mathrm{mM})$ and the radioactivity was measured to determine the amount of labeled iron incorporated during the incubation time Gamma emission was counted using a PerkinElmer gamma counter. Iron uptake of heterologous pyoverdine was expressed in percentage terms compared with the homologous pyoverdine uptake.

\section{Statistical Analyses}

Statistics were evaluated with the Statgraphics Plus v.5.1. software (Statistical Graphics Corp., Herndon, VA, United States). Data are means of three independent determinations and were subjected to one- or two-way analysis of variance (ANOVA) 


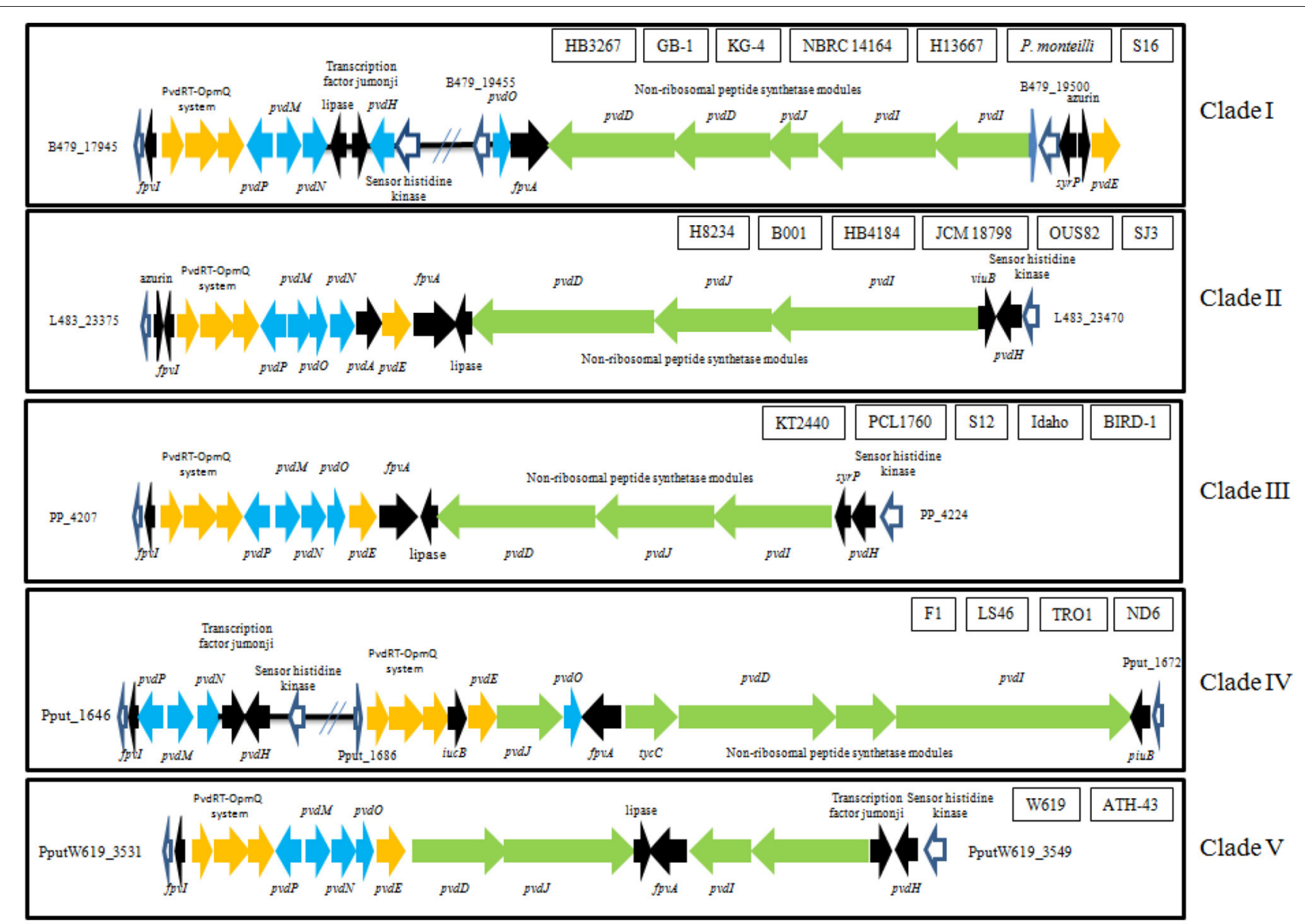

FIGURE 1 | Organization of the pyoverdine locus in representative $\boldsymbol{P}$. putida strains of every clade found. Green arrows symbolize genes involved in non-ribosomal peptide synthesis modules, yellow/orange arrows indicate genes involved in pyoverdine transport or recycling, blue arrows indicate genes involved in pyoverdine maturation, black arrows other genes involved in pyoverdine biosynthesis and white arrows are genes not directly involved in pyoverdine biosynthesis. Genes without a name, no specific function was found.

followed by Tukey posthoc test $(p \leq 0.01)$ when a significant difference was detected.

\section{RESULTS}

\section{Diversity of Pyoverdine Loci in P. putida Strains}

The genes which are typically involved in pyoverdine synthesis, transport, and perception are conserved in P. putida strains (Figure 1). All the genomes analyzed contain the genes that encode PvdH, PvdP, PvdM, PvdN, PvdO that are involved in the pyoverdine chromophore maturation and PvdD, PvdJ, PvdI which are involved in the synthesis of the peptidic part of the pyoverdine (the non-ribosomal peptide synthetase module). They also contained $p v d E$, a gene that encodes a protein for the export of the pyoverdine precursor peptide to the periplasm, and $p v d R, p v d T$, and $o p m Q$ and $f v p A$. PvdRT and OpmQ mediate the transport of the newly synthesized pyoverdine across the outer membrane and the recycling of pyoverdines. The FvpA receptor is a TonB-transporter family protein involved in pyoverdine-Fe sensing and internalization (Imperi et al., 2009; Cornelis, 2010; Schalk and Guillon, 2013; Gasser et al., 2015; Chen et al., 2016). $f p v I$ that encodes for a RNA polymerase ECF-type sigma factor is also present in all the strains at the same locus. Although all the genes are present in the analyzed genomes, their organization varies depending on the P. putida strain (Figure 1).

$P$. putida strains can be grouped into 5 different clades on the basis of the percentage of identity shared by the proteins encoded in the pyoverdine locus (each clade was defined when the overall amino-acid identity was higher than $80 \%$; Tables $\mathbf{1}$, 2, Figure 1). Strains in Clade I can be classified into two subclades, each one sharing an identity higher than 95\%. (Tables 1, 2). Subclade A includes the clinical isolates P. putida HB13667, HB3267 and the waste-water strain P. putida JLR11, (Tables 1, 2). Subclade B included the waste-water strains P. taiwanensis SJ9 and P. monteilii SB3101; the rhizosphere strain S16 and the soil and naphthalene degrader strain KG-4. The aquatic strain GB1 and the clinical strain NBRC 14164T form a less homogeneous sub-clade; the amino-acid identity of the pyoverdine locus among the strains of this subclade did not reach $90 \%$ (Table 2). In all the 


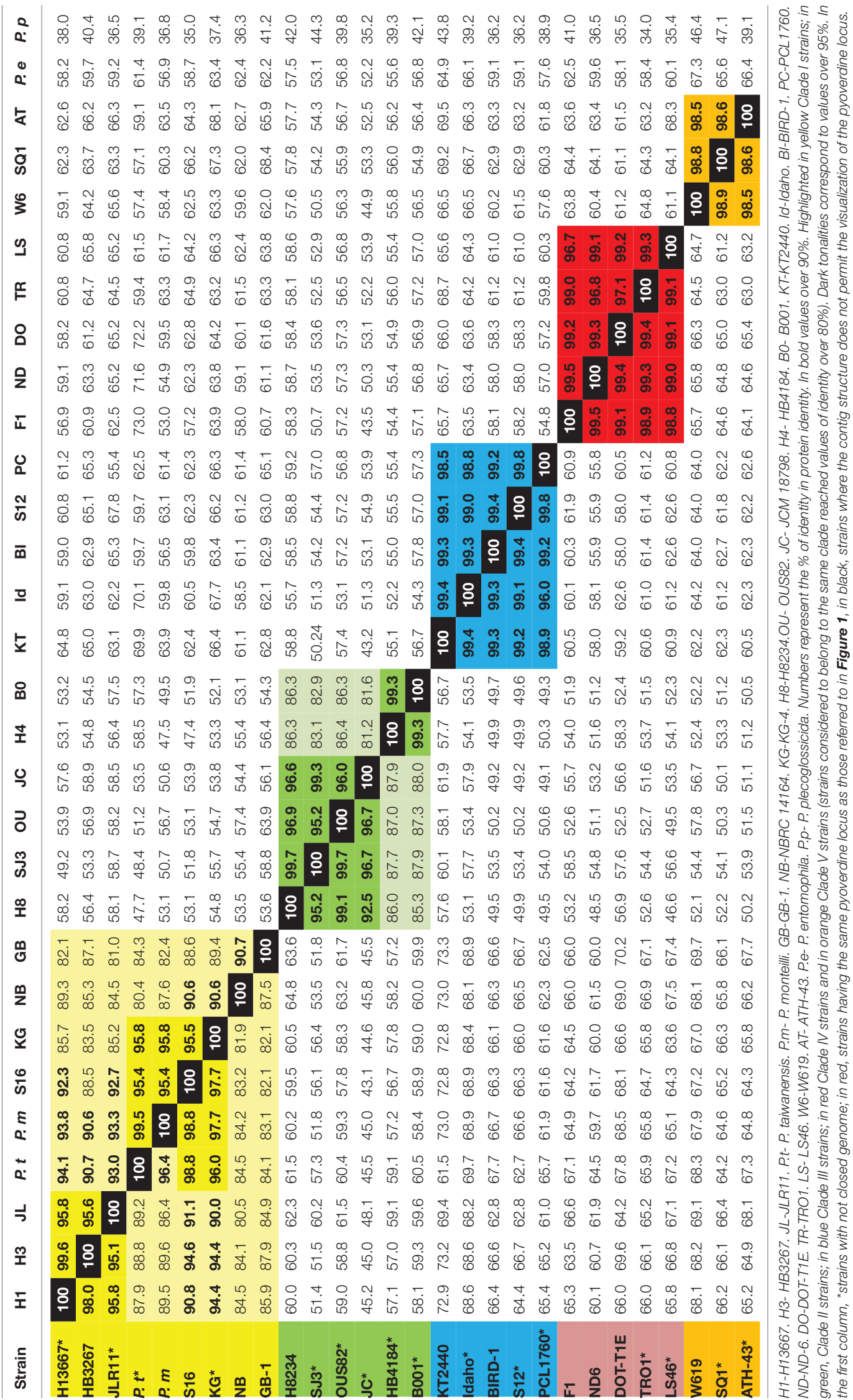


strains forming Clade I, the pyoverdine genes are located in two loci in different locations in the chromosome (Table 1, Figure 1).

Clade II can also be divided into two subclades (Tables 1, 2). The first one includes the clinical strains P. putida H8234 and JCM 18798; P. putida SJ3, a waste-water and caprolactam degrader strain, with the soil isolate and naphthalene degrader $P$. putida OUS82 (Tables 1, 2). Overall amino-acid identity amongst the pyoverdine locus of the four strains within the subclade is higher than $95 \%$. The second subclade includes the clinical strain P. putida HB4184 and the rhizobacterium B001 (Table 2). In all the strains forming Clade II, the pyoverdine genes are located in a single locus in the chromosome (Table 1, Figure 1).

Clade III and IV are very homogeneous (Tables 1, 2). Clade III comprises strains that showed more than $98 \%$ identity in the pyoverdine-related proteins. As in Clade II, the pyoverdine genes are located in a single locus in all the strains forming Clade III, Table 1, Figure 1). Clade IV, includes strains with an overall identity $>96 \%$, and comprises only water isolates, such as the toluene degrading strains P. putida F1 and DOT-T1E, the naphthalene degrader ND6, the triclosan degrader TR01, and the polyhydroxyalkanoate synthesizer LS46 (Tables 1, 2). In all these strains the pyoverdine genes are located in two different loci (Table 1, Figure 1), with the exception of $P$. putida DOT$\mathrm{T} 1 \mathrm{E}$ that presents three loci associated with pyoverdine synthesis (Table 1).

The endophitic strain W619, with strain SQ1 isolated from lake sediment and the Antarctic isolate ATH-43 are found in Clade V (Tables 1, 2). In Clade V, the pyoverdine genes are located in a single locus in the chromosome (Table 1, Figure 1).

Two bacteria, traditionally considered close relatives of the P. putida group (Molina et al., 2016), were included in this study; the entomopathogen P. entomophila L48 (Vodovar et al., 2006), and the fish pathogen $P$. plecoglossicida DSM 15088 (Nishimori et al., 2000). None of them presented an identity higher than $68 \%$ at this locus when compared to the rest of the P. putida strains (Table 2), indicating the different evolution of these strains in terms of siderophore production and perception.

Bioinformatic prediction of the composition of the peptide sequences of different pyoverdines from several fluorescent Pseudomonas was performed by Ye et al. (2013). This study supports our clade classification. Furthermore, we have predicted the pyoverdine peptide sequences of the strains not previously included in Ye et al. (2013) and our results show that all the strains included in a clade have the same peptide sequence (Table 1). The consensus sequence for the pyoverdine peptide obtained for Clade II strains (Table 1) is Asp-5hOrn-LysThr/Gly- a peptide that was not previously predicted by Ye et al. (2013) and that is clearly different from the sequences of other clades.

To experimentally confirm the in silico results, we carried out IEF siderotyping assays on representative strains of each of the clades defined in this work (except strains from Clade $\mathrm{V}$ that were not available in our lab). We found that strains belonging to one clade had similar pyoverdine production profiles and that the profile of strains within a clade was different from that of strains belonging to other clades (Figure 2).
Our bioinformatic and experimental results suggest that the average identity of genes forming part of the pyoverdine locus, together with bioinformatics using the predictor NRPSsp, can easily discriminate the type of pyoverdine produced by the different strains within the species $P$. putida, instead of more laborious techniques such as siderotyping.

\section{Pyoverdine Production by Clinical Strains vs. Environmental Strains}

In silico analysis of pyoverdine loci grouped the strains of $P$. putida HB13667 and HB3267 in Clade I with 98\% sequence identity; both had been isolated from human blood. Although $P$. putida NBRC14164T was also grouped in Clade I, it belonged to a different subclade sharing a lower amino-acid identity (84\%) with HB13667 and HB3267. P. putida H8234, H4184, and JCM18798 (with an overall identity of $86 \%$ ) grouped into Clade II and were clearly separated from the other three clinical strains identity below 65\% (Table 2). This suggests that siderophorerelated proteins of the clinical isolates have at least two different phylogenic origins.

Interestingly, the pyoverdine-related proteins of isolate HB4184, isolated from human sputum, showed an identity close to $99.0 \%$ with $P$. putida B001 (Table 2), a rhizobacterium that was isolated from shore sand, oligotrophic and high salinity environment (Park et al., 2011; Table 2). To investigate if pyoverdine production in $P$. putida HB4184 was induced under high salt concentrations, we analyzed their production in a medium with the standard salt concentration used in laboratory media $(0.05 \% \mathrm{w} / \mathrm{v} \mathrm{NaCl})$ and in the same medium but with $0.9 \% \mathrm{w} / \mathrm{v} \mathrm{NaCl}$ content, in the presence or absence of the iron chelator EDDHA. Pyoverdine is secreted to the media in poor iron conditions; consequently, production of siderophores under iron rich conditions was barely perceptible in all the strains tested regardless of the salinity of the media (Figure 3). In the absence of free iron ions (in the presence of the iron chelator EDDHA) the production of a pyoverdine-type siderophore was increased in both media. This increase was especially significant in the environmental strains $P$. putida KT2440 and BIRD1 under standard laboratory medium. Production of pyoverdine was induced in the presence of high salt concentrations in all the clinical strains tested, but not in the environmental strains. This increase was significantly higher in strain P. putida HB4184 (Figure 3). This experiment suggests that clinical strains are better adapted to uptake iron under high salinity conditions than the environmental strains, with P. putida HB4184 being especially adapted to this condition.

\section{The Diversity of the FpvA Pyoverdine Transporters in $P$. putida}

Analysis of the homology amongst $P$. putida proteins involved in the synthesis and maturation of the chromophore part, in the transport of the peptidic part of pyoverdine or the complete siderophore, which are encoded by some genes of the pyoverdine locus, showed that they are highly conserved in all the $P$. putida studied strains (with an identity in the range between 75 and 90\%). However, the identity percentage 


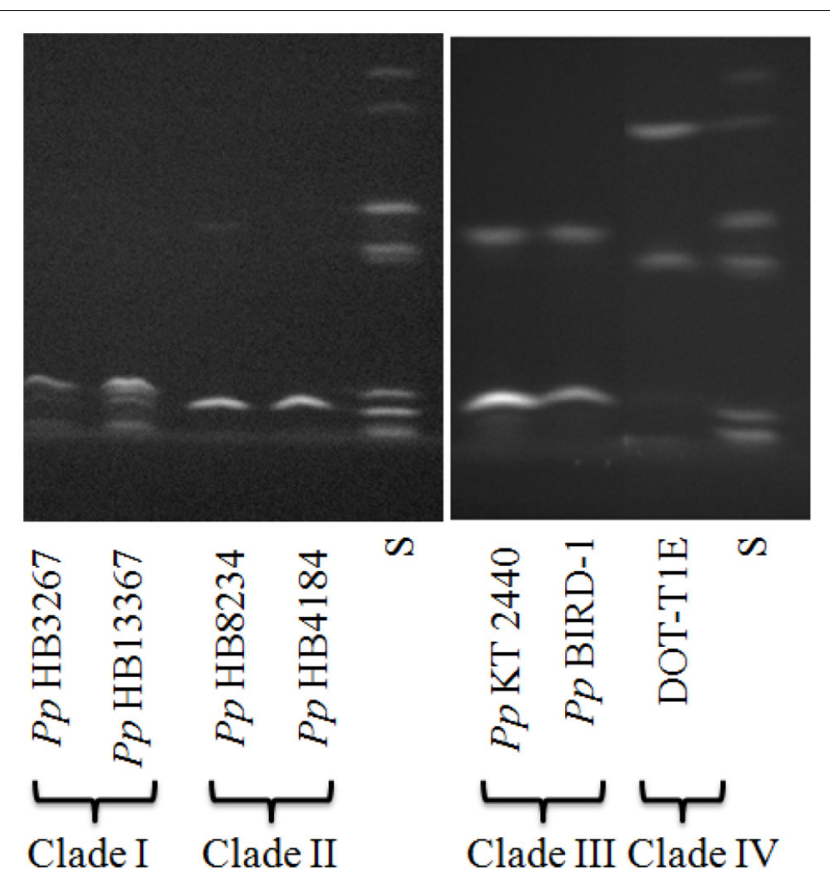

FIGURE 2 | IEF profiles of pyoverdines synthesized by the different $\boldsymbol{P}$. putida strains. $S$ corresponds to the molecular weight standard.

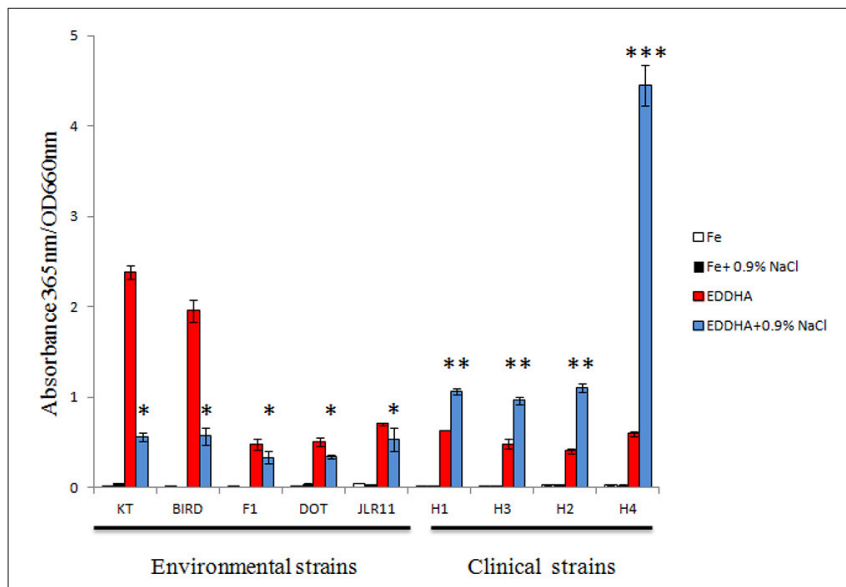

FIGURE 3 | Pyoverdine production by $\boldsymbol{P}$. putida strains at low and a human serum osmolarity conditions. KT, KT2440; DOT, DOT-T1E; H1, HB13667; H3, HB3267; H2, H8234; and H4, HB4184. Error bars mean standard deviation of 3 independent replicates. ${ }^{*},{ }^{* *}$, and ${ }^{* \star *}$ means statistically differenced groups $(p<0.01)$

diminished when the pyoverdine receptor protein (FpvA) or the non-ribosomal peptide synthesis module PvdD, PvdJ, PvdI were analyzed (identity below 65\% in most cases; data not shown). A similar observation was reported in $P$. aeruginosa strains by Smith et al. (2005). These authors proposed that the FpvA protein may be driving diversity at the pyoverdine locus. The outer membrane receptor FpvA, involved in the internalization of the pyoverdine-Fe complex following extracellular iron chelation, is specific for one pyoverdine type (Meyer et al., 2002; Smith et al., 2005; Nader et al., 2011). In P. aeruginosa three structurally different types of pyoverdine (types I, II, III) are produced, and each one is recognized at the outer membrane by the specific receptors, FpvAI, FpvAII, and FpvAIII, respectively (Cornelis et al., 1989).

Classification of $P$. putida strains on the basis of the homology only amongst FpvA proteins gave a similar grouping of strains than when we used the complete pyoverdine locus (Table 1, Figure 4). Strains included in Clade I and II appear to belong to the classical FpvA receptor group (FpvA-I) where the FpvA type protein is similar to the FpvA of $P$. aeruginosa that recognizes the pyoverdine type I (Nader et al., 2011; Table 1, Figure 4). However, FpvA sequences of strains previously classified as Clade II are phylogenetically more distant to the sequences of strains belonging to Clade I; therefore we suggest that they may constitute different subgroups (Table 1, Figure 4).

Strains belonging to Clade III presented homology with an alternative receptor of type I pyoverdine named FpvB (Ghysels et al., 2004; Table 1, Figure 4). P. putida FpvA proteins belonging to Clade III are phylogenetically separated from other members of the group that are not $P$. putida species, such as Pseudomonas protegens Pf-5 (Hassan et al., 2010), Pseudomonas chlororaphis subsp. aureofaciens 30-84 (Loper et al., 2012), and P. protegens CHA0 (Ramette et al., 2011; Table 1, Figure 4). In the P. putida strains used in this study, the $f p v A$ gene codifying the FpvB receptor is part of the pyoverdine locus (Figure 1) whilst in $P$. aeruginosa this gene is located elsewhere in the chromosome (Ghysels et al., 2004).

FpvA proteins of strains in Clade IV form a highly homogeneous group, which is related to the FpvA-III receptor from the opportunistic human pathogen $P$. aeruginosa PAO1 (Szmolka et al., 2012; Figure 4).

The FpvA protein of the endophitic strain W619 and strains SQ1 and ATH-43 (Clade V) form part of a different group of receptors, closer to that of Pseudomonas sp. GM84, a strain isolated from rhizosphere/endosphere of Populus deltoides (Brown et al., 2012).

Interestingly, P. putida JLR11, HB13667, HB3267 FpvA proteins were at least $98 \%$ identical, suggesting a common origin of this transporter in these three strains (Table 1, Figure 4). FpvA from HB4184 shows high homology (98\%) with the rhizobacterium $P$. putida B001, isolated from a sandy shore soil from the Yellow Sea.

To sum up, the results described above indicate that phylogenetic studies based on the FpvA protein sequence of different $P$. putida strains yielded the same five clades that have been defined on the basis of overall protein homology with the pyoverdine-related genes (Table 1, Figure 4).

\section{Other Siderophore Transporters}

Pseudomonas strains are also able to obtain iron through the acquisition of siderophores produced by other microorganisms (xenosiderophores) by TonB-dependent transporters located in their outer membrane (Schalk and Guillon, 2013). The function and number of TonB-dependent transporters in a particular strain have been related to their ability to adapt to changing environments and to colonize new niches (Cornelis, 2010; Llamas 


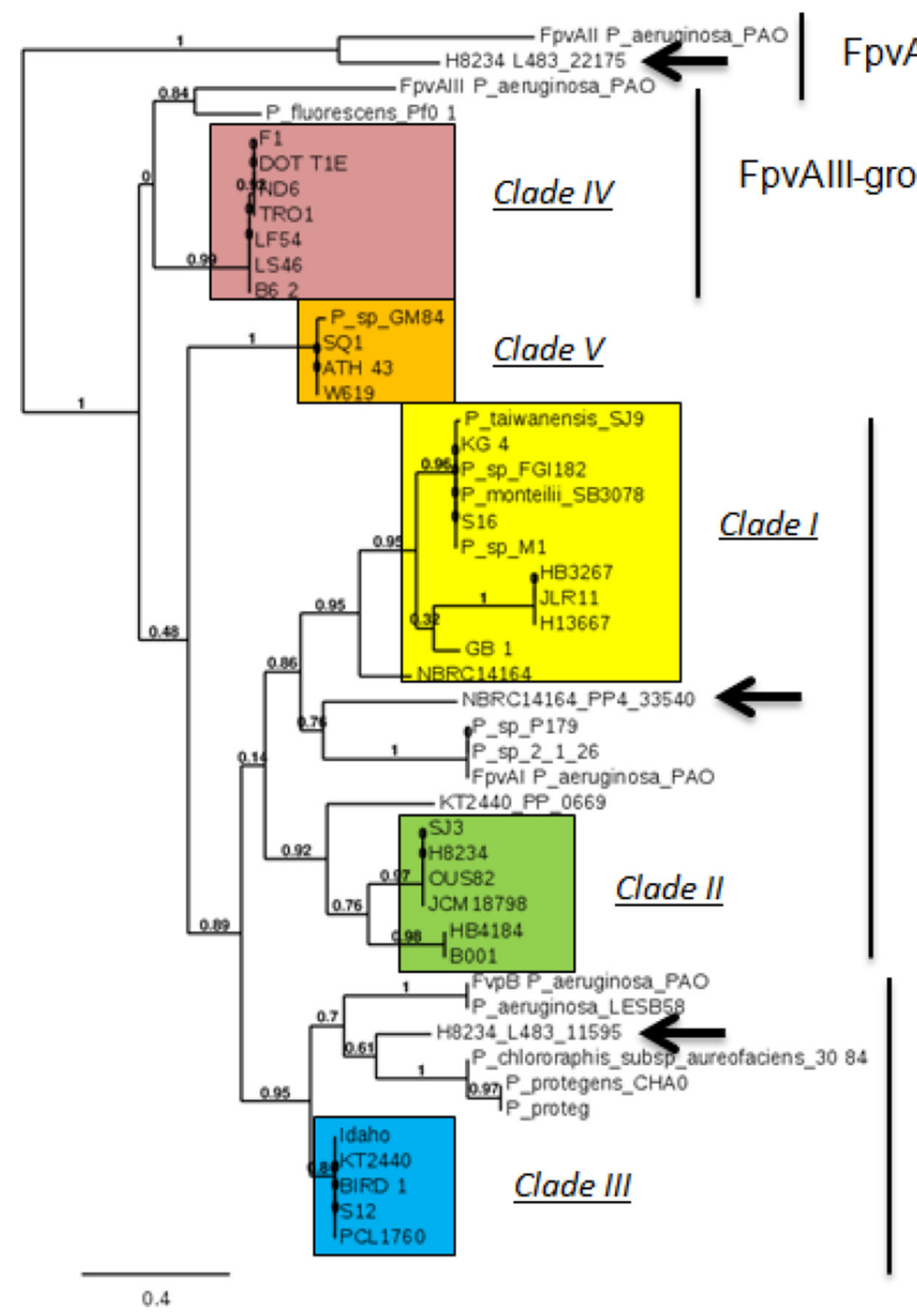

\section{FpvAl-group}

\section{FpvB-group}

FIGURE 4 | Phylogenetic three of the FpvA proteins from different Pseudomonas strains. Arrows represent exclusive TonB transporters from clinical strains. Clades are marked in the figure (square in yellow Clade I strains, in green Clade II strains, in blue Clade III strains, in red Clade IV strains, and in orange Clade V strains. Arrows indicate other TonB-dependent receptors from the studied strains that phylogenetically belong to the FpvA group. Software used to generate figure was Phylogeny.fr.

et al., 2014). TonB-dependent transporters are made up of three domains: the first one, a $\beta$-barrel with 11 large extracellular loops and periplasmic turns. The lumen of this barrel is occluded by a globular domain, which is the second domain, called the "plug" and the third domain consists of a long periplasmic Nterminal extension that is not involved in the transport of iron siderophores but participates in the regulation of transcription (Noinaj et al., 2010).

Analysis of the genome sequence of the $P$. putida strains revealed the presence of 7-14, depending on the strain, TonBdependent transporters with these three domains, (Table 1, Supplementary Table 1). Remarkably, strains belonging to subclade A of Clade II and those belonging to subclade C or Clade I possess the highest number of these transporters (from 19 to 25) (Table 1, Supplementary Table 2). The presence of a higher number of TonB-dependent transporters than in the other $P$. putida strains seems to indicate that strains belonging to these subclades may have more versatility to acquire iron sources.

Most of the TonB-dependent transporters of the clinical strains P. putida HB13667, HB3267, and HB4184 are similar to those present in other $P$. putida strains (Supplementary Table 2), indicating than they are able to recognize the same type of xenosiderophores; this kind of transporter is considered to be non-exclusive. However, P. putida H8234 
possesses two exclusive TonB-dependent transporters that have no homologs in any other $P$. putida strains we have studied. These transporters, namely L483_22175 and L483_11595, have their closest homologs in transporters identified in $P$. aeruginosa strains. L483-22175 presents $83 \%$ identity with $P$. aeruginosa isolates identified in cystic fibrosis patients (De Vos et al., 2001) and belongs to the FpvAII group (Figure 4) whilst L483_11595 belongs to the FpvB group (Figure 4) and its closest homolog (77\% identity) was found in opportunistic human pathogens, i.e., $P$. aeruginosa strains PAO and LESB58. These results indicate that the $P$. putida isolate $\mathrm{H} 8234$ is able to recognize different siderophores from those recognized by other $P$. putida strains.

\section{Siderophore Uptake by $\boldsymbol{P}$. putida Strains}

To investigate the incorporation of different pyoverdines produced by several Pseudomonas strains, we measured the incorporation of $P$. putida siderophores bound with ${ }^{55} \mathrm{Fe}$ into several $P$. putida strains. Siderophores produced by $P$. putida strains belonging to the same clade incorporated $100 \%$ of the complex siderophore- ${ }^{55} \mathrm{Fe}$, with the only exception of $P$. putida HB4184 that was only able to uptake the $48.2 \%$ of siderophores produced by $P$. putida H8234. These two strains belong to different subclades, and differences at the level of pyoverdinerelated proteins may account for this differential uptake. Crossincorporation of siderophores between strains belonging to different clades was inferior to $4 \%$.

As previously mentioned, the outer membrane TonBdependent transporters are involved in the internalization of the xenosiderophore-Fe complexes and therefore we tested if siderophores produced by $P$. aeruginosa strains can be taken up by $P$. putida strains. In these assays we used the strains $P$. aeruginosa $\mathrm{PAO} 1$ that produces pyoverdine type $\mathrm{I}, P$. aeruginosa 27,853 that produces pyoverdine type II, and P. aeruginosa Pa6 that produces pyoverdine type III. The level of siderophore (probably pyoverdine) cross-incorporation was below $10 \%$ in all cases, with the exception of $P$. putida DOT-T1E that was able to incorporate $18.8 \%$ of the siderophore-Fe complexes of P. aeruginosa strain PAO1, $21.7 \%$ of strain 27,853 and $73.8 \%$ of strain Pa6 (Table 3).

In agreement with our phylogenetic studies of the FpvA protein, strains with FpvA proteins included in the FpvA-I and FpvB type of receptors (Figure 4), known to recognize pyoverdine type I (Cornelis et al., 1989; Ghysels et al., 2004) and belonging to Clade I, II, and III recognized the siderophores produced by the $P$. aeruginosa PAO1 (which mainly produces pyoverdine type I) better than siderophores produced by the other two P. aeruginosa strains (Table 3). Also in agreement with our classification, $P$. putida DOT-T1E (belonging to Clade IV and with FpvA protein included in the FpvA- III group; Figure 4), uptook siderophores more specifically produced by $P$. aeruginosa strain $\mathrm{Pa} 6$ (which mainly produces pyoverdine type III).

\section{DISCUSSION}

Traditionally the "core" genome of a species has been defined as those genes shared by all the strains of the species and amongst them, are included the majority of genes with housekeeping
TABLE 3 | Cross-incorporation of pyoverdine between different Pseudomonas strains.

\begin{tabular}{|c|c|c|c|c|c|c|c|}
\hline \multirow[b]{2}{*}{ Strains } & \multicolumn{2}{|c|}{ Clade I } & \multicolumn{2}{|c|}{ Clade II } & \multicolumn{2}{|c|}{ Clade III } & \multirow{2}{*}{$\begin{array}{l}\text { Clade IV } \\
\text { DOT-T1E }\end{array}$} \\
\hline & HB13667 & HB3267 & H8234 & HB4184 & KT2440 & BIRD-1 & \\
\hline HB13667 & 100 & 100 & 0 & & & 0.7 & 0 \\
\hline H8234 & 2.8 & & 100 & 48.2 & & 1.2 & 0 \\
\hline KT2440 & & & & & 100 & 100 & \\
\hline DOT-T1E & 3.5 & & 0 & & & 1.3 & 100.0 \\
\hline PAO1 & 6.1 & 1.5 & 7.9 & 9.1 & & 4.1 & 18.8 \\
\hline 27853 & 0.3 & 0.4 & 1.5 & 0.4 & & 2.1 & 21.7 \\
\hline $\mathrm{Pa6}$ & 1.3 & 0 & 4.3 & 0 & & 0 & 73.8 \\
\hline
\end{tabular}

Numbers refers to the mean of percentage of pyoverdine ( $P v d)$ uptake compared to the incorporation of the native Pvd. In the first column, the strain source of pyoverdine, the second line the names of the uptaking strains. Highlighted in grey, maximum pyoverdine uptake; in bold, the highest values of siderophore from $P$. aeruginosa uptaken by $P$. putida strains (statistically differenced $p<0.01$ ). These experiments were repeated at least twice, deviation errors were less than the $10 \%$ of the mean in all cases.

functions. These genes are interspersed with "accessory" genomic elements that are present in some but not all strains of the species (Kung et al., 2010). The accessory genome normally consists of integrative and conjugative elements, gene islands, prophages and phage-like elements, transposons, insertion sequences, and integrons (Mazel, 2016). The accessory genome of an individual strain is considered as an important driver of its ability to evolve and persist in a particular environment (RodriguezValera et al., 2016). Therefore, niche adaptation is the result of interplay between "canonical" core genes and accessory genes. Interestingly, in $P$. aeruginosa the pyoverdine genes have been described as having a "core-accessory" character; they are present in all the strains that make up the species, but their codon usage, especially of the $f p v A$ and the non-ribosomal peptide synthetase module genes, is different from the rest of the genes of the genome (Smith et al., 2005). This latter characteristic is specific to accessory genes, and is an indication of a differential evolution rate (Udaondo et al., 2016). This different codon usage is not consequence of direct acquisition from other microorganisms, but rather of the accumulation of polymorphisms and positive selection of these genes, which contribute to niche adaptation (Yang et al., 2012).

In this study we have classified the $P$. putida strains in five clades according to the global homology of the proteins codified by the pyoverdine loci. This distribution of strains in clades gave a similar but not identical phylogeny than that resulting from the basis of global genome phylogeny (Supplementary Figure 1) and the total proteome identity (Supplementary Table 1). Whilst the phylogeny based on pyoverdine locus, genome and proteome analysis is identical for all the isolates included in Clades II and $\mathrm{V}$, genome and proteome phylogeny of strains included in Clades III and IV did not reveal the same pattern as the analysis with the pyoverdine locus (Supplementary Figure 1, Supplementary Table 1 ), suggesting a different evolution rate of the pyoverdine genes in these P. putida strains.

The high sequence homology of the protein encoded in the pyoverdine locus and the FpvA protein of the clinical isolates 
P. putida HB13667 and HB3267 (both isolated from blood of immune-depressed patients [Molina et al., 2016]), and the wastewater isolate JLR11 (included in Clade I, subclade A; Table 1), suggests that they either have a common ancestor or that the three strains have transited through similar environments and adapted to particular iron conditions. Waste water can be the equivalent to a laboratory for the fast evolution of bacteria: different bacterial strains coexist in these habitats and are exposed to pollutants coming from multiple human activities (agriculture, industry, and others). Bacterial survival under these conditions implies the acquisition of new capacities or the evolution of existing ones (Sharma et al., 2016). P. putida has an open-pangenome (Udaondo et al., 2016) and the acquisition of accessory genes and the evolution of those already existing in the core may help to colonize new environments. Gene acquisition from these niches has been demonstrated to be involved the capacity of some of $P$. putida strains to resist multiple antibiotics and the degradation of toxic compounds used in medicine, industry, and agriculture (Molina et al., 2013, 2014, 2016; Udaondo et al., 2016). However, the average total protein identity amongst the three strains is $>95 \%$, significantly higher than the identity with other strains of Clade I, thus reinforcing the idea of a common ancestor for the three strains.

The availability of iron is a frequent restrictive condition for the optimal growth of a microorganism in a given habitat and competition for its uptake is fierce in order to survive. The genomes of three of the clinical strains studied encode eight $(P$. putida HB13667 and HB3267) and ten (P. putida HB4184) TonBdependent transporters related with xenosiderophore uptake that are similar to those identified in other environmental strains, suggesting that these strains acquire iron and perceive it in human fluids (from which they have been isolated) through uptake systems similar to those of environmental strains and that they have not acquired distinctive systems for the acquisition of xenosiderophores. Accordingly, their capacity to uptake siderophores from other Pseudomonas strains (i.e., $P$. aeruginosa) is quite limited (Table 3 ). The other three clinical strains $P$. putida H8234, NBRC14164T, and JCM18798 possess a high number of TonB-dependent transporters (1920) (Table 1). These results suggest that these three clinical strains might be better suited for competing with other bacteria for iron scavenging. However, we did not observe significant differences in pyoverdine uptake in the different strains (Table 3), probably because these TonB-dependent transporters have not been related with pyoverdine uptake but rather with the uptake of different siderophores. Pyoverdine uptake has been related (Cornelis et al., 1989; Ghysels et al., 2004) with the type of FvpA-type therefore, strains belonging to Clade I and II uptake siderophores secreted by $P$. aeruginosa PAO1 that mainly produce pyoverdine type I, whilst $P$. putida DOTT1E present the highest levels of uptake with siderophores produced by $P$. aeruginosa $\mathrm{Pa} 6$ (secreting mainly pyoverdine type III).

Pyoverdine-related genes systems of strain P. putida HB4184 are closely related to those of $P$. putida B001, a strain isolated from sandy shore soil and probably adapted to high salinity conditions. This similarity suggests that this clinical strain could be better adapted to uptake iron from environments with high osmotic pressure and this hypothesis was confirmed by the observation of a higher production of pyoverdine under iron deprivation conditions and in the presence of $0.9 \%$ of $\mathrm{NaCl}$ than the rest of the strains tested. P. putida HB4184 was isolated from sputum of an immuno-depressed patient with cystic fibrosis and although the normal concentrations of sodium and chloride ions in human saliva are lower than in serum, the concentrations of potassium, bicarbonate and iodine are higher. Furthermore, it has been reported than osmolarity in sputum from cystic fibrosis patients is higher than those in normal secretions, due to higher mucin concentrations in the secretions of these patients (Henderson et al., 2014). The induction of iron scavenging mechanisms under high salt conditions may be relevant under specific clinical conditions.

\section{CONCLUDING REMARKS}

The P. putida isolates which we studied can be classified into different clades according to the genetics of the siderophore biosynthesis and iron recycling (the identity of all the genes which make up the pyoverdine locus/i). In the case of the clinical strains, this classification suggests at least two possible different origins for these strains.

P. putida HB4184 (isolated from human sputum) is well adapted to uptake iron under high osmolarity conditions, a property that could be relevant for survival in specific human environments (such as sputum). P. putida H8234 and NBRC14164T possess unique TonB-dependent transporters, not found in any other clinical or environmental strains and therefore seem to be well adapted to compete with other microorganisms for iron scavenging.

The different phylogenetic origins of the pyoverdine locus in the $P$. putida clinical strains and the peculiarities of some of these strains suggest that either the clinical environment does not represent a high selective pressure in terms of iron scavenge and that the human environment is very diverse and adaptation of the different strains is mainly driven by these different conditions, or that $P$. putida strains are newcomers in hospital environments and that the ironscavenge systems have had not enough time to evolve common mechanisms.

\section{AUTHOR CONTRIBUTIONS}

Conceived and designed the experiments: LM, VG, JR. Performed the experiments: LM, VG, ZU. Analyzed the data: LM, VG, ZU, AS, JR. Wrote the paper: LM, VG, AS, JR.

\section{ACKNOWLEDGMENTS}

Work in our laboratories was supported by ERANET Pathogenomics program through the ADHERS project (Ref: BIO2008-04419-E) and Fondos FEDER from the European 
Union through project BIO2010-17227 of the Spanish Ministry of Economy and Competitivity. The work in Abengoa Research was funded by H2020 grant Empowerputida number 65703. We thank Gwenaëlle Graulier and Caroline Choufa for their technical assistance.

\section{REFERENCES}

Abril, M. A., Michán, C., Timmis, K. N., and Ramos, J. L. (1989). Regulator and enzyme specificities of the TOL plasmid-encoded upper pathway for degradation of aromatic hydrocarbons and expansion of the substrate range of the pathway. J. Bacteriol. 171, 6782-6790.

Aziz, R. K., Bartels, D., Best, A. A., DeJongh, M., Dis, T., Edwards, R. A., et al. (2008). The RAST Server: rapid annotations using subsystems technology. BMC Genomics. 9:75. doi: 10.1186/1471-2164-9-75

Bogaerts, P., Bouchahrouf, W., Lissoir, B., Denis, O., and Glupczynski, Y. (2011). IMP-13-producing Pseudomonas monteilii recovered in a hospital environment. J. Antimicrob. Chemother. 66, 2434-2435. doi: $10.1093 /$ jac/dkr294

Brown, S. D., Utturkar, S. M., Klingeman, D. M., Johnson, C. M., Martin, S. L., Land, M. L., et al. (2012). Twenty-one genome sequences from Pseudomonas species and 19 genome sequences from diverse bacteria isolated from the rhizosphere and endosphere of Populus deltoides. J. Bacteriol. 194, 5991-5993. doi: 10.1128/JB.01243-12

Bultreys, A., Gheysen, I., Maraite, H., and de Hoffmann, E. (2001). Characterization of fluorescent and nonfluorescent peptide siderophores produced by Pseudomonas syringae strains and their potential use in strain identification. Appl. Environ. Microbiol. 67, 1718-1727. doi: 10.1128/AEM.67.4.1718-1727.2001

Chen, W., Kuo, T. Y., Hsieh, F. C., Chen, P. Y., Wang, C. S., Shih, Y. L., et al. (2016). Involvement of type VI secretion system in secretion of iron chelator pyoverdine in Pseudomonas taiwanensis. Sci. Rep. 8:32950. doi: $10.1038 /$ srep32950

Cornelis, P. (2010). Iron uptake and metabolism in pseudomonads. Appl. Microbiol. Biotechnol. 86, 1637-1645. doi: 10.1007/s00253-010-2550-2

Cornelis, P., Hohnadel, D., and Meyer, J. M. (1989). Evidence for different pyoverdine-mediated iron uptake systems among Pseudomonas aeruginosa strains. Infect. Immun. 57, 3491-3497.

Dawar, C., and Aggarwal, R. K. (2015). Draft genome sequence of hydrocarbondegrading Pseudomonas putida Strain KG-4, isolated from soil samples collected from Krishna-Godavari Basin in India. Genome Announc. 3, e00590e00515. doi: 10.1128/genomeA.00590-15

Dereeper, A., Guignon, V., Blanc, G., Audic, S., Buffet, S., Chevenet, F., et al. (2008). Phylogeny.fr: robust phylogenetic analysis for the non-specialist. Nucleic Acids Res. 36, W465-W469. doi: 10.1093/nar/gkn180

De Vos, D., de Chial, M., Cochez, C., Jansen, S., Tummler, B., Meyer, J. M., et al. (2001). Study of pyoverdine type and production by Pseudomonas aeruginosa isolated from cystic fibrosis patients: prevalence of type II pyoverdine isolates and accumulation pyoverdine-negative mutations. Arch. Microbiol. 175, 384-388. doi: 10.1007/s002030100278

Felux, A. K., Franchini, P., and Schleheck, D. (2015). Permanent draft genome sequence of sulfoquinovose-degrading Pseudomonas putida strain SQ1. Stand. Genom. Sci. 10, 42. doi: 10.1186/s40793-015-0033-x

Fernández, M., Conde, S., Duque, E., and Ramos, J. L. (2013). In vivo gene expression of Pseudomonas putida KT2440 in the rhizosphere of different plants. Microb. Biotechnol. 6, 307-313. doi: 10.1111/1751-7915. 12037

Fuchs, R., Schafer, M., Geoffroy, V., and Meyer, J. M. (2001). Siderotyping - a powerful tool for the characterization of pyoverdines. Curr. Top. Med. Chem. 1, 31-57. doi: 10.2174/1568026013395542

Galli, E., Silver, S., and Witholt, B. (Eds.). (1992). Pseudomonas: Molecular Biology and Biotechnology. Washington, DC: American Society for Microbiology.

García-Salamanca, A., Molina-Henares, M. A., van Dillewijn, P., Solano, J., Pizarro-Tobías, P., Roca, A., et al. (2013). Bacterial diversity in the rhizosphere

\section{SUPPLEMENTARY MATERIAL}

The Supplementary Material for this article can be found online at: http://journal.frontiersin.org/article/10.3389/fmicb. 2016.02100/full\#supplementary-material

of maize and the surrounding carbonate-rich bulk soil. Microb. Biotechnol. 6, 36-44. doi: 10.1111/j.1751-7915.2012.00358.x

Gasser, V., Guillon, L., Cunrath, O., and Schalk,. I. J. (2015). Cellular organization of siderophore biosynthesis in Pseudomonas aeruginosa: evidence for siderosomes. J. Inorg. Biochem. 148, 27-34. doi: 10.1016/j.jinorgbio.2015.01.017

Ghysels, B., Dieu, B. T., Beatson, S. A., Pirnay, J. P., Ochsner, U. A., Vasil, M. L., et al. (2004). FpvB, an alternative type I ferripyoverdine transporter of Pseudomonas aeruginosa. Microbiology 150, 1671-1680. doi: $10.1099 / \mathrm{mic} \cdot 0.27035-0$

Hassan, K. A., Johnson, A., Shaffer, B. T., Ren, Q., Kidarsa, T. A., Elbourne, L. D., et al. (2010). Inactivation of the GacA response regulator in Pseudomonas fluorescens Pf-5 has far-reaching transcriptomic consequences. Environ. Microbiol. 12, 899-915. doi: 10.1111/j.1462-2920.2009.02134.x

Henderson, A. G., Ehre, C., Button, B., Abdullah, L. H., Cai, L. H., Leigh, M. W., et al. (2014). Cystic fibrosis airway secretions exhibit mucin hyperconcentration and increased osmotic pressure. J. Clin. Invest. 124, 3047-3060. doi: 10.1172/JCI73469

Hong, S. J., Park, G. S., Khan, A. R., Jung, B. K., Park, Y. J., Yoo, N. K., et al. (2015). Draft Genome Sequence of Caprolactam-Degrading Pseudomonas putida Strain SJ3. Genome Announc. 3, e00810-e00815. doi: 10.1128/genomeA.00810-15

Hong, S. J., Park, G. S., Khan, A. R., Jung, B. K., and Shin, J. H. (2016). Draft genome sequence of a caprolactam degrader bacterium: Pseudomonas taiwanensis strain SJ9. Braz. J. Microbiol. 2, S1517-S8382(16)00079-4. doi: 10.1016/j.bjm.2015.09.002

Imperi, F., Tiburzi, F., and Visca, P. (2009). Molecular basis of pyoverdine siderophore recycling in Pseudomonas aeruginosa. Proc. Natl. Acad. Sci. U.S.A. 106, 20440-20445. doi: 10.1073/pnas.0908760106

Koedam, N., Wittouck, E., Gaballa, A., Gillis, A., Hofte, M., and Cornelis, P. (1994). Detection and differentiation of microbial siderophores by isoelectric focusing and chrome azurol S overlay. Biometals 7, 287-291.

Kung, V. L., Ozer, E. A., and Hauser, A. R. (2010). The accessory genome of Pseudomonas aeruginosa. Microbiol. Mol. Biol. Rev. 74, 621-641. doi: 10.1128/MMBR.00027-10

Li, S., Zhao, H., Li, Y., Niu, S., and Cai, B. (2012). Complete genome sequence of the naphthalene-degrading Pseudomonas putida strain ND6. J. Bacteriol. 194, 5154-5155. doi: 10.1128/JB.01190-12

Llamas, M. A., Imperi, F., Visca, P., and Lamont, I. L. (2014). Cell-surface signaling in Pseudomonas: stress responses, iron transport, and pathogenicity. FEMS Microbiol. Rev. 38, 569-597. doi: 10.1111/1574-6976.12078

Loper, J. E., Hassan, K. A., Mavrodi, D. V., Davis, E. W. II, Lim, C. K., Shaffer, B. T., et al. (2012). Comparative genomics of plant-associated Pseudomonas spp.: insights into diversity and inheritance of traits involved in multitrophic interactions. PLoS Genet. 8:e1002784. doi: 10.1371/journal.pgen.1002784

Maki, H., Masuda, N., Fujiwara, Y., Ike, M., and Fujita, M. (1994). Degradation of alkylphenol ethoxylates by Pseudomonas sp. strain TR01. Appl. Environ. Microbiol. 60, 2265-2271.

Martínez-Bueno, M. A., Tobes, R., Rey, M., and Ramos, J. L. (2002). Detection of multiple extracytoplasmic function (ECF) sigma factors in the genome of Pseudomonas putida KT2440 and their counterparts in Pseudomonas aeruginosa PA01. Environ. Microbiol. 4, 842-855. doi: 10.1046/j.1462-2920.2002.00371.x

Matilla, M. A., Pizarro-Tobias, P., Roca, A., Fernandez, M., Duque, E., Molina, L., et al. (2011). Complete genome of the plant growth-promoting rhizobacterium Pseudomonas putida BIRD-1. J. Bacteriol. 193, 1290. doi: 10.1128/JB.01281-10

Matthijs, S., Laus, G., Meyer, J. M., Abbaspour-Tehrani, K., Schafer, M., Budzikiewicz, H., et al. (2009). Siderophore-mediated iron acquisition in the entomopathogenic bacterium Pseudomonas entomophila L48 and 
its close relative Pseudomonas putida KT2440. Biometals 22, 951-964. doi: 10.1007/s10534-009-9247-y

Mazel, D. (2016). Integrons: agents of bacterial evolution. Nat. Rev. Microbiol. 4, 608-620. doi: 10.1038/nrmicro1462

Meyer, J. M. (2000). Pyoverdines: pigments, siderophores and potential taxonomic markers of fluorescent Pseudomonas species. Arch. Microbiol. 174, 135-142. doi: $10.1007 / \mathrm{s} 002030000188$

Meyer, J. M., Geoffroy, V. A., Baysse, C., Cornelis, P., Barelmann, I., Taraz, K., et al. (2002). Siderophore-mediated iron uptake in fluorescent Pseudomonas: characterization of the pyoverdine-transporter binding site of three cross-reacting pyoverdines. Arch. Biochem. Biophys. 397, 179-183. doi: 10.1006/abbi.2001.2667

Meyer, J. M., Gruffaz, C., Raharinosy, V., Bezverbnaya, I., Schafer, M., and Budzikiewicz, H. (2008). Siderotyping of fluorescent Pseudomonas: molecular mass determination by mass spectrometry as a powerful pyoverdine siderotyping method. Biometals 21, 259-271. doi: 10.1007/s10534-007-9115-6

Meyer, J. M., Gruffaz, C., Tulkki, T., and Izard, D. (2007). Taxonomic heterogeneity, as shown by siderotyping, of strains primarily identified as Pseudomonas putida. Int. J. Syst. Evol. Microbiol. 57, 2543-2556. doi: 10.1099/ijs.0.65233-0

Molina, L., Bernal, P., Udaondo, Z., Segura, A., and Ramos, J. L. (2013). Complete genome sequence of a Pseudomonas putida clinical isolate, strain H8234. Genome Announc. 1, e00496-e00413. doi: 10.1128/genomeA.00496-13

Molina, L., Ramos, C., Duque, E., Ronchel, M. C., Garcia, J. M., Wike, L., et al. (2000). Survival of Pseudomonas putida KT2440 in soil and in the rhizosphere of plants under greenhouse and environmental conditions. Soil Biol. Biochem. 32, 315-321. doi: 10.1016/S0038-0717(99)00156-X

Molina, L., Udaondo, Z., Duque, E., Fernández, M., Bernal, P., Roca, A., et al. (2016). Specific gene loci of clinical Pseudomonas putida Isolates. PLoS ONE 11:e0147478. doi: 10.1371/journal.pone.0147478

Molina, L., Udaondo, Z., Duque, E., Fernández, M., Molina-Santiago, C., Roca, A., et al. (2014). Antibiotic resistance determinants in a Pseudomonas putida strain isolated from a hospital. PLoS ONE 9:e81604. doi: 10.1371/journal.pone.0081604

Nader, M., Journet, L., Meksem, A., Guillon, L., and Schalk, I. J. (2011). Mechanism of ferripyoverdine uptake by Pseudomonas aeruginosa outer membrane transporter FpvA: no diffusion channel formed at any time during ferrisiderophore uptake. Biochemistry 50, 2530-2540. doi: 10.1021/bi101821n

Nelson, K. E., Weinel, C., Paulsen, I. T., Dodson, R. J., Hilbert, H., Martins dos Santos, V. A., et al. (2002). Complete genome sequence and comparative analysis of the metabolically versatile Pseudomonas putida KT2440. Environ. Microbiol. 4, 799-808. doi: 10.1046/j.1462-2920.2002.00366.x

Nishimori, E., Kita-Tsukamoto, K., and Wakabayashi, H. (2000). Pseudomonas plecoglossicida sp. nov., the causative agent of bacterial haemorrhagic ascites of ayu, Plecoglossus altivelis. Int. J. Syst. Evol. Microbiol. 50(Pt 1), 83-89. doi: 10.1099/00207713-50-1-83

Noinaj, N., Guillier, M., Barnard, T. J., and Buchanan, S. K. (2010). TonBdependent transporters: regulation, structure, and function. Annu. Rev. Microbiol. 64, 43-60. doi: 10.1146/annurev.micro.112408.134247

Ohji, S., Yamazoe, A., Hosoyama, A., Tsuchikane, K., Ezaki, T., and Fujita, N. (2014). The complete genome sequence of Pseudomonas putida NBRC 14164T confirms high intraspecies variation. Genome Announc. 2, e00029-e00014. doi: 10.1128/genomeA.00029-14

Park, J. Y., Han, S. H., Lee, J. H., Han, Y. S., Lee, Y. S., Rong, X., et al. (2011). Draft genome sequence of the biocontrol bacterium Pseudomonas putida B001, an oligotrophic bacterium that induces systemic resistance to plant diseases. J. Bacteriol. 193, 6795-6796. doi: 10.1128/JB.06217-11

Pascual, J., Udaondo, Z., Molina, L., Segura, A., Esteve-Núñez, A., Caballero, A., et al. (2015). Draft Genome Sequence of Pseudomonas putida JLR11, a facultative anaerobic 2,4,6-Trinitrotoluene biotransforming bacterium. Genome Announc. 3, e00904-e00915. doi: 10.1128/genomeA.00904-15

Payne, S. M. (1980). Synthesis and utilization of siderophores by Shigella flexneri. J. Bacteriol. 143, 1420-1424.

Planchamp, C., Glauser, G., and Mauch-Mani, B. (2015). Root inoculation with Pseudomonas putida KT2440 induces transcriptional and metabolic changes and systemic resistance in maize plants. Front. Plant. Sci. 5:719. doi: 10.3389/fpls.2014.00719

Ramette, A., Frapolli, M., Fischer-Le Saux, M., Gruffaz, C., Meyer, J. M., Défago, G., et al. (2011). Pseudomonas protegens sp. nov., widespread plant-protecting bacteria producing the biocontrol compounds 2,4diacetylphloroglucinol and pyoluteorin. Syst. Appl. Microbiol. 34, 180-188. doi: 10.1016/j.syapm.2010.10.005

Rodriguez-Valera, F., Martin-Cuadrado, A. B., and López-Pérez, M. (2016). Flexible genomic islands as drivers of genome evolution. Curr. Opin. Microbiol. 31, 154-160. doi: 10.1016/j.mib.2016.03.014

Hoegy F. 1., and Schalk, I. J. (2014). Monitoring iron uptake by siderophores. Methods Mol. Biol. 1149, 337-346. doi: 10.1007/978-1-4939-0473-0_28

Schalk, I. J., and Guillon, L. (2013). Pyoverdine biosynthesis and secretion in Pseudomonas aeruginosa: implications for metal homeostasis. Environ. Microbiol. 15, 1661-1673. doi: 10.1111/1462-2920.12013

Sharma, P. K., Fu, J., Cicek, N., Sparling, R., and Levin, D. B. (2012). Kinetics of medium-chain-length polyhydroxyalkanoate production by a novel isolate of Pseudomonas putida LS46. Can. J. Microbiol. 58, 982-989. doi: 10.1139/w2012-074

Sharma, V. K., Johnson, N., Cizmas, L., McDonald, T. J., and Kim, H. (2016). A review of the influence of treatment strategies on antibiotic resistant bacteria and antibiotic resistance genes. Chemosphere 150, 702-714. doi: 10.1016/j.chemosphere.2015.12.084

Smith, E. E., Sims, E. H., Spencer, D., Kaul, R., and Olson, M. V. (2005). Evidence for diversifying selection at the pyoverdine locus of Pseudomonas aeruginosa. J. Bacteriol. 187, 2138-2147. doi: 10.1128/JB.187.6.2138-2147.2005

Szmolka, A., Cramer, N., and Nagy, B. (2012). Comparative genomic analysis of bovine, environmental, and human strains of Pseudomonas aeruginosa. FEMS Microbiol. Lett. 335, 113-122. doi: 10.1111/j.1574-6968.2012.02642.x

Tao, F., Shen, Y., Fan, Z., Tang, H., and Xu, P. (2012). Genome sequence of Pseudomonas putida S12, a potential platform strain for industrial production of valuable chemicals. J. Bacteriol. 194, 5985-5986. doi: 10.1128/JB.01482-12

Tao, F., Tang, H., Gai, Z., Su, F., Wang, X., He, X., et al. (2011). Genome sequence of Pseudomonas putida Idaho, a unique organic-solvent-tolerant bacterium. $J$. Bacteriol. 193, 7011-7012. doi: 10.1128/JB.06200-11

Tay, M., Roizman, D., Cohen, Y., Tolker-Nielsen, T., Givskov, M., and Yang, L. (2014). Draft genome sequence of the model naphthalene-utilizing organism Pseudomonas putida OUS82. Genome Announc. 2, e01161-e01113. doi: 10.1128/genomeA.01161-13

Udaondo, Z., Duque, E., Fernandez, M., Molina, L., de la Torre, J., Bernal, P., et al. (2012). Analysis of solvent tolerance in Pseudomonas putida DOT-T1E based on its genome sequence and a collection of mutants. FEBS Lett. 586, 2932-2938. doi: 10.1016/j.febslet.2012.07.031

Udaondo, Z., Molina, L., Daniels, C., Gómez, M. J., Molina-Henares, M. A., Matilla, M. A., et al. (2013). Metabolic potential of the organic-solvent tolerant Pseudomonas putida DOT-T1E deduced from its annotated genome. Microb. Biotechnol. 6, 598-611. doi: 10.1111/1751-7915.12061

Udaondo, Z., Molina, L., Segura, A., Duque, E., and Ramos, J. L. (2016). Analysis of the core genome and pangenome of Pseudomonas putida. Environ. Microbiol. 18, 3268-3283. doi: 10.1111/1462-2920.13015

Visca, P., Imperi, F., and Lamont, I. L. (2007). Pyoverdine siderophores: from biogenesis to biosignificance. Trends Microbiol. 15, 22-30. doi: 10.1016/j.tim.2006.11.004

Vodovar, N., Vallenet, D., Cruveiller, S., Rouy, Z., Barbe, V., Acosta, C., et al. (2006). Complete genome sequence of the entomopathogenic and metabolically versatile soil bacterium Pseudomonas entomophila. Nat. Biotechnol. 24, 673-679. doi: 10.1038/nbt1212

von Graevenitz, A., and Weinstein, J. (1971). Pathogenic significance of Pseudomonas fluorescens and Pseudomonas putida. Yale J. Biol. Med. 44, 265-273.

Wu, X., Monchy, S., Taghavi, S., Zhu, W., Ramos, J., and van der Lelie, D. (2011). Comparative genomics and functional analysis of niche-specific adaptation in Pseudomonas putida. FEMS Microbiol. Rev. 35, 299-323. doi: 10.1111/j.1574-6976.2010.00249.x

$\mathrm{Xu}, \mathrm{Z}$., and Hao, B. (2009). CVTree update: a newly designed phylogenetic study platform using composition vectors and whole genomes. Nucleic Acids Res. 37(Web Server issue), W174-W178. doi: 10.1093/nar/gkp278

Yang, M., Lv, Y., Xiao, J., Wu, H., Zheng, H., Liu, Q., et al. (2012). Edwardsiella comparative phylogenomics reveal the new intra/inter-species taxonomic relationships, virulence evolution and niche adaptation mechanisms. PLoS ONE 7:e36987. doi: 10.1371/journal.pone.0036987

Ye, L., Ballet, S., Hildebrand, F., Laus, G., Guillemyn, K., Raes, J., et al. (2013). A combinatorial approach to the structure elucidation of a 
pyoverdine siderophore produced by a Pseudomonas putida isolate and the use of pyoverdine as a taxonomic marker for typing $P$. putida subspecies. Biometals 26, 561-575. doi: 10.1007/s10534-0139653-Z

Yoshino, Y., Kitazawa, T., Kamimura, M., Tatsuno, K., Ota, Y., and Yotsuyanagi, H. (2011). Pseudomonas putida bacteremia in adult patients: five case reports and a review of the literature. J. Infect. Chemother. 17, 278-282. doi: 10.1007/s10156-010-0114-0

Yu, H., Tang, H., Wang, L., Yao, Y., Wu, G., and Xu, P. (2011). Complete genome sequence of the nicotine-degrading Pseudomonas putida strain S16. J. Bacteriol. 193, 5541-5542. doi: 10.1128/JB.05663-11
Conflict of Interest Statement: The authors declare that the research was conducted in the absence of any commercial or financial relationships that could be construed as a potential conflict of interest.

Copyright (c) 2016 Molina, Geoffroy, Segura, Udaondo and Ramos. This is an openaccess article distributed under the terms of the Creative Commons Attribution License (CC BY). The use, distribution or reproduction in other forums is permitted, provided the original author(s) or licensor are credited and that the original publication in this journal is cited, in accordance with accepted academic practice. No use, distribution or reproduction is permitted which does not comply with these terms. 